\title{
Cutaneous manifestation in pregnancy
}

\section{Original Research Article}

\author{
Mahendra $^{1}$, Peta B. ${ }^{2}$, Vijaya Lakshmi ${ }^{3}$ \\ ${ }^{1}$ Dr. Mahendra, Associate Professor, ${ }^{2}$ Dr. Bharathi Peta, Post Graduate. ${ }^{3}$ Prof. Dr. Vijaya Lakshmi, Professor and HOD, all \\ authors are affiliated with Department of Obstetrics and Gynaecology, Adichunchungiri Institute of Medical Science, \\ Mandya, Karnataka, India.
}

Corresponding Author: Dr. Bharathi Peta, Post Graduate, Department of Obstetrics and Gynaecology, Adichunchungiri Institute of Medical Science, Mandya, Karnataka, India, Email: bharathipeta@gmail.com

\begin{abstract}
Back ground: During pregnancy there is immunologic, metabolic, endocrine and vascular changes responsible for physiological and pathological skin changes. Aims and Objectives: The objectives of the study to determine the pattern of the skin changes associated withpregnancy and to examine in detail both physiological and specific dermatosis. To identify the various clinical types of pregnancyspecific physiological changes and to know the proportion of these cutaneous manifestation in pregnant women. Materials and Method: The study was a cross sectional study carried out at the out patient department of gynaecological and obstetrics at Adhichunchanagiri Institute of Medical Sciences, Bellur, Karnataka. Study was a period of 6 months. A total of 200 pregnant females, irrespective of their parity and gestational age were examined for any dermatological complaint. Result: The age of the study population ranged from 17 to 39 years (mean=24years), the study population included 200, (60\%) primigravida, 40\% multigravida. Skin changes were grouped in to: physiological changes (all cases), other dermatoses affected by pregnancy ( 80 cases), specific dermatoses ( 20 cases). Most common physiological changes were pigmentary alteration 184 cases (92\%), followed by straie seen in 172 cases (86\%). Of the various specific dermatoses of pregnancy, Pruritic utricarial papules and plaques of pregnancy was the most common disorder (13 cases), followed by Pruritus gravidarum (6 cases). The most common dermatoses affected by pregnancy Vulvovaginal candidiasis (30 cases), acne vulgaris (20 cases), eczemas (10 cases). Conclusion: Pregnant women are prone to suffer from a wide range of dermatological problems apart from specific dermatoses of pregnancy. The study emphasizes the need for a detailed and meticulous examination of these patients to detect various disorders.
\end{abstract}

Keywords: Pregnancy dermatoses, Specific dermatoses, Pruritus gravidarum

\section{Introduction}

In pregnancy cutaneous changes results from altered metabolic, immunological and endocrine factors. These changes are the positive adaptation of mother to accommodate and support the fetus as it develops through gestation [1]. Physiological skin changes in pregnancy include changes in pigmentation, alteration in connective tissue, vascular system as well as changes in hairs and nails [2]. Some skin eruptions are specific to pregnancy and are called pregnancy specific dermatosis.

Along with this, the pre-existing skin conditions may either improve or exacerbate in pregnancy due to immunological changes in pregnancy. As cell mediated immunity is depressed during normal pregnancy, this accounts for increased severity and frequency of skin infections as candidiasis. However, detailed reports

Manuscript received: $5^{\text {th }}$ September 2018

Reviewed: $15^{\text {th }}$ September 2018

Author Corrected: $24^{\text {th }}$ September 2018

Accepted for Publication: $30^{\text {th }}$ September 2018

Obsgyne Review: Journal of Obstetrics and Gynecology encompassing the physiological changes and specific dermatoses of pregnancy and its effects of various dermatoses on these women are scanty in literature. Many studies have focused on a particular dermatosis or other diseases and condition related to pregnancy $[1,2]$. Existing studies show a wide range of variations in the incidence of Specific dermatoses of pregnancy. For these reasons, a clinical study was conducted to study both physiological changes and specific dermatoses of pregnancy.

The detailed reports encompassing the physiological changes and pregnancy specific dermatosis and effects of various dermatosis on pregnant women are scanty in literature. Correct diagnosis is important for management and also for prognosis because some of the skin disorders like Pemphigiod gestation are associated with fetal risk. For this reasons a clinical study was conducted to study both physiological changes and pregnancy specific dermatosis.

Available online at: www.medresearch.in $62 \mid \mathrm{P}$ a g e 


\section{Materials and Methods}

An observational cross-sectional study was conducted, which included 200 consecutive pregnant women attending the Obstetrics and Gynecology Department of Adichunchanagiri Institute of Medical Science, Karnataka. Ethics Committee clearance and informed consent of patients were obtained.

Inclusion Criteria: All pregnant women having symptoms related to skin and mucosa

Exclusion Criteria: Medical disorders associated with skin lesions

Drug reactions: A total of 200 patients were included in this study for a period of 6 months. The age of our study population ranged from 17 years to 39 years, with a majority being in the 23-25-year age group. Detailed

\section{Original Research Article}

history of patients including chief complaint of itching and skin lesions, onsetin relation to duration to pregnancy, vaginal discharge. Detailed medical history and examination, Obstetric detailssuch as period of gestation and obstetric score were also noted.

Detailed dermatological examination was performed for patients to look for physiological changes and specific dermatoses. In case of specific dermatosesthe morphology of skin lesions, distribution, and site involved were studied.

The diagnosis was based mainly on clinical grounds, history of a pre-existing skin disease also noted a routine examination of blood and urine and serology were done in all cases.

\section{Results}

Most cases were primigravida 120 (60\%); 80 (40\%) were multigravida. Commonest physiological changes encountered was Pigmentary 184 (92\%), followed by Stria 172(86\%) (Table 1).

Table-1: Physiological changes in pregnancy.

\begin{tabular}{|l|c|c|}
\hline Physiological changes & No.of patient out of 200 & Percentage(\%) \\
\hline 1. Pigmentary changes & 184 & 92 \\
\hline 2. Striae distensae & 172 & 86 \\
\hline 3. Linea Nigra & 176 & 88 \\
\hline 4. Melasma & 24 & 12 \\
\hline 5. Non pittingoedema of feet & 21 & 10.5 \\
\hline 6. Venous varicosities & 4 & 2.5 \\
\hline 7. Pregnancy gingivitis & 5 & 6 \\
\hline 8. Montgomery's tubercles & 12 & 0 \\
\hline 9. Palmars erythema & 0 & 2 \\
\hline
\end{tabular}

In Specific dermatoses of pregnancy, Pruritic urticarial papules \& plaques of pregnancy 13(6.5\%) is the commonest followed by Prurutis gravidarum 6 (3\%) and Intrahepatic cholestasis of pregnancy $1(0.5 \%)$ (Table 2).

Table-2: Specific dermatoses of pregnancy

\begin{tabular}{|c|c|c|}
\hline Type of Specific dermatoses of pregnancy & No.of Cases out of 200 & Percentage (\%) \\
\hline $\begin{array}{c}\text { Polymorphic eruption of pregnancy (PEP) } \\
\text { (Pruritic urticarial papules \& plaques of pregnancy } \\
\text { Toxic erythema of pregnancy) }\end{array}$ & 13 & 6.5 \\
\hline $\begin{array}{c}\text { Atopic eruption of pregnancy (AEP) } \\
\text { Prurigo of Pregnancy } \\
\text { Pruritic folliculitis of pregnancy) }\end{array}$ & 6 & 3 \\
\hline $\begin{array}{c}\text { Pemphigoid gestations (PG)/ } \\
\text { Herpes gestationis }\end{array}$ & 0 & 0 \\
\hline $\begin{array}{c}\text { Intrahepatic Cholestasis Pregnancy (ICP) } \\
\text { (Obstetric cholestasis }\end{array}$ & 1 & 0.5 \\
\hline Pruritus/ Prurigo gravidarum) & & \\
\hline
\end{tabular}

Skindisease affected by pregnancy includes Vulvovaginal candidiasis 30 (15\%), Eczema 10 (5\%), Acne vulgaris 20 (10\%) Tineaversicolor 5 (2.5\%), Scabies 5 (2.5\%) (Table 3). 
Original Research Article

Table-3: Disease affected by pregnancy.

\begin{tabular}{|l|c|c|}
\hline Type of dermatological disease & No.of cases out of 200 & Percentage (\%) \\
\hline 1.Acne vulgaris & 20 & 5 \\
\hline 2.Eczema & 10 & 2.5 \\
\hline 3.Scabies & 5 & 2.5 \\
\hline 4.Herpes zoster & 4 & 2.5 \\
\hline 5.Tinea versicolor & 5 & 15 \\
\hline 6.Pityriasis rosea & 5 & 0.5 \\
\hline 7.Vulvovaginal candidiasis & 30 & 2 \\
\hline 8.Itchyosis vulgaris & 1 & 2 \\
\hline
\end{tabular}

\section{Discussion}

Pregnancy is a unique physiological state characterized by metabolic, immunologic, and hormonal readjustments. These make a pregnant woman vulnerable to all dermatoses occurring in the nonpregnant state and also to certain eruptions related to the physiologic burden of gestation. Many of the symptoms and signs are so common that they are not usually considered as being abnormal, but regarded as physiological and can sometimes provide contributory evidence of pregnancy [4]. The most common physiological changes are pigmentalterations, stretch marks, vascular changes and Telogen effluvium [3].

In this study, most women 184 (92\%) experienced physiological changes. In a study by Kumari et al[4], physiological changes were observed in all patients studied $(100 \%)$. In the study by Raj et al [5], which included 1175 pregnant women, only 114 (9.7\%) experienced some skin changes.Among the physiological changes, the most common was hyperpigmentation seen in $526(87.67 \%)$ cases.

The mostcommon pattern was lineanigra (fig.1) seen in $87.67 \%$ of the patients. Even in the study by Kumari et al[4], the most common pattern of hyperpigmentation was reported to be lineanigra, which was noted in $91.4 \%$ of the patients. In our study, pigmentchangeswere seen in $92 \%$ of the cases. Melasma (fig. 2 ) was found in $12 \%$ of the patients in our study. Raj et al [5] observed melasma in $10 / 1175(8.5 \%)$ cases and Kumari et al [4] reported an incidence of $2.5 \%$. The frequency of striae gravidarum (fig.3) was $86 \%$ in our study. The atrophic form of striae was common among multigravidas $(76.95 \%)$, whereas the purplish form was common among primigravidas (45.67\%). Shivakumar and Madhavamurthy [6] reported a frequency of $66.47 \%$ for atrophic striae. Kumari et al[4] reported that striae were seen in $484(79.7 \%)$ cases, of which 217 (44.8\%) were primigravidas and 267 (55.2\%) were multigravidas.

Obsgyne Review: Journal of Obstetrics and Gynecology
Vascular changes are congruent with pregnancy because the gravid state increases blood volume, vascular dilatation, capillary permeability, and neovascularization, a process believed to be related to the increase in estrogen and angiogenicfactors. Vascular changes seen in our study include nonpitting edema of feet in $10.5 \%$ of the cases and venous varicosities (fig. 4 ) in $2 \%$ of the cases. No cases of palmar erythema were seen in our study. Raj. et al. [5] reported the prevalence of palmar erythema to be $33.3 \%$. Pregnancy gingivitis is due to hormonal changes as well as local Irritation, nutritional deficiencies may also be responsible [3]. It was seen in $5 / 200$ patients in our study. In a study by Muzzaffar et al. [7], 23/140 (16.4\%) had gingival edema and redness.

Increased appearance of Montgomery's tubercles is wellknown during pregnancy in $30-50 \%$ of pregnant women [3]. In our study, Montgomery's tubercles were seen in $6 \%$ of the patients.

An increased frequency of infection was seen in our study, which is common during pregnancy and is probably related to low cellular immunity. During pregnancy, the cells of the hyperplastic vaginal epithelium get filled with glycogen, desquamate, and contribute to low vaginal acidity, thereby creating an environment suitable for growth of Candida. We found vulvovaginal candidiasis in $15 \%$ of patients, Other infections seen were tinea versicolor $(2.5 \%)$, scabies $(2.5 \%)$, pityriasis rosea $(2.5 \%)$, and acne vulgaris $(10 \%)$.

Nail changes such as brittleness, subungual hyper keratosis, oncholysis and leuconychia have been reported during pregnancy. However, no significant nail changes in pregnant females were observed in our study.

Specific dermatoses of pregnancy represent a heterogeneous group of ill-defined pruritic skin diseases unique to pregnancy. Holmes and Black [11] proposed a

Available online at: www.medresearch.in 64 | P a g e 
simplified clinical classification of the specific dermatoses of pregnancy. This classification basically subdivided the specific dermatoses of pregnancy into the following four groups: Pemphigoid (herpes) gestation, Polymorphic eruption of pregnancy, Prurigo of pregnancy,Pruritic folliculitis of pregnancy [11].

Based on the study conducted by Ambros-Rudolph et. Al [12] on 505 pregnant patients, a new classification has been proposed and introduced a new term called "atopic eruption of pregnancy," which covers all patients formerly diagnosed as having prurigo of pregnancy, pruritic folliculitis, and eczema of pregnancy. The incidence of these specific disorders of pregnancy is $0.5-3.0 \%$ [8]. In our study of 200 women, $20(10 \%)$ cases of specific dermatoses were seen. Of these, the most common was polymorphic eruption of pregnancy is $13 \mathrm{cases}$ (6.5\%)(fig.5) Two recent studies from India $(9,13)$ reported a higher prevalence, with PEP being the most common PSDs in their respective studies. PEP ocuurs in 1 of 160- 240 pregnancies and is more common in white women [14]. It occurs classically in primigravida duringthe third trimester of pregnancy or occasionally postpartum and does not reoccur in subsequent pregnancies. Incidence of PEP is higher in multiple gestation. All the affected patients in our study were primigravida and all carried single gestationpregancies.

In the study by Shivakumar and Madhavamurthy[6], 16 (9.4\%) patients had prurigo of pregnancy, six (3.52\%) had pruritus gravidarum, and four $(2.35 \%)$ had polymorphic eruption. In the study by Kumari et al[4], the incidence of specific dermatoses was $3.6 \%$. In a recent Indian study by Puri and Puri [9], the commonest pregnancy-related dermatoses were polymorphic eruption of pregnancy $(22 \%)$, prurigo of pregnancy $(7 \%)$, pemphigoid gestation $(3 \%)$, pruritic folliculitis of pregnancy $(2 \%)$, and intra hepatic cholestasis (1\%).Another Indian study, however, reported the commonpregnancy-specific dermatoses to be prurigo of pregnancy[10].

\section{Conclusion}

Physiological dermatoses are common in primigravida compared to multigravida. Infective dermatosis during pregnancy should be diagnosed at the earliest to prevent morbidity during antenatal period. Specific dermatoses of pregnancy are also not uncommon, can be a source of significant distress to the patients which warrants specific care in turn influences the maternal and fetal outcome. The awareness, recognition of these skin conditions, familiarity with their treatment, antepartum surveillance, early diagnosis and prompt treatment is essential for improving maternal and fetal prognosis thus minimizes their morbidity.

Obsgyne Review: Journal of Obstetrics and Gynecology

\section{Original Research Article}

Fetal risks have only been associated with PG and ICP, but with the overlappingsymptoms between the diseases pruritis in pregnancy should never be neglected.

Interdisciplinary management involving dermatologists, pediatricians, obstetricians, and gastroenterologists is mandatory to acquire a better outcome for the mother and the fetus.

\section{Funding: Nil, Conflict of interest: Nil Permission from IRB: Yes}

\section{References}

1.Kroumpouzos G, Cohen LM. Dermatoses of pregnancy. J Am Acad Dermatol. 2001 Jul;45(1):1-19; quiz 19-22. DOI:10.1067/mjd.2001.114595

2. Shornick JK, Bangert JL, Freeman RG, Gilliam JN. Herpes gestationis: clinical and histologic features of twenty-eight cases. J Am Acad Dermatol. 1983 Feb;8 (2): 214-24.

3. Martin AG, Leal-Khouri S. Physiologic skin changes associated with pregnancy. Int J Dermatol. 1992 Jun;31 (6): 375-8.

4. Kumari R, Jaisankar TJ, Thappa DM. A clinical study of skin changes in pregnancy. Indian J Dermatol Venereol Leprol. 2007 Mar-Apr;73(2):141.

5. Raj S, Khopkar U, Kapasi A, Wadhawa SL. Skin in pregnancy. Indian J Dermatol Venereol Leprol. 1992; 58: 84-8.

6. Shivakumar V, Madhavamurthy P. Skin in pregnancy. Indian J Dermatol VenereolLeprol. 1999 Jan-Feb;65(1): 23-5.

7. Muzaffar F, Hussain I, Haroon TS. Physiologic skin changes during pregnancy: a study of 140 cases. Int J Dermatol. 1998 Jun;37(6):429-31.

8. Roger D, Vaillant L, Fignon A, et al. Specific pruritic diseases of pregnancy. A prospective study of 3192 pregnant women. Arch Dermatol. 1994 Jun; 130 (6): 734-9.

9. Puri N, Puri A. A study on dermatoses of pregnancy. Our Dermatol Online.2013;4:56-60. 130:734-9.

10. Hassan I, Bashir S, Taing S. A clinical study of the skin changes in pregnancy in Kashmir valley of north India: a hospital based study. Indian J Dermatol. 2015 Jan-Feb;60 (1): 28-32. doi: 10. 4103/ 0019-5154.147782.

Available online at: www.medresearch.in $65 \mid \mathrm{P}$ a g e 
11. Holmes RC, Black MM. The specific dermatoses of pregnancy. J Am Acad Dermatol. 1983 Mar; 8 (3):405-12.

12. Ambros-Rudolph CM, Müllegger RR, Vaughan-Jones $\mathrm{SA}$, et al. The specific dermatoses of pregnancy revisited and reclassified: results of a retrospective two-center study on 505 pregnant patients. J Am Acad Dermatol. 2006 Mar; 54 (3): 395-404. DOI: 10.1016/j. jaad. 2005. 12.012

13. Kumari R, Jaisankar TJ, Thappa DM. A clinical study of skin changes in pregnancy. Indian $\mathrm{J}$ Dermatol VenereolLeprol. 2007 Mar-Apr;73(2):141.

\section{Original Research Article}

14. Aronson IK, Bond S, Fiedler VC, et al. Pruritic urticarial papules and plaques of pregnancy: clinical and immunopathologic observations in 57 patients. J Am Acad Dermatol. 1998 Dec;39(6):933-9.

15. Pennoyer JW, Grin CM, Driscoll MS, et al. Changes in size of melanocytic nevi during pregnancy. J Am Acad Dermatol. 1997 Mar;36(3 Pt 1):378-82.

16. Cohen LM, Capeless EL, Krusinski PA, Maloney ME. Pruritic urticarial papules and plaques of pregnancy and its relationship to maternal-fetal weight gain and twin pregnancy. Arch Dermatol. 1989 Nov;125(11):1534-6.

\section{How to cite this article?}

Mahendra, Peta B, Vijaya Lakshmi. Cutaneous manifestation in pregnancy. Obs Rev:J obstet Gynecol 2018;4 (3): 62-66.doi:10.17511/joog.2018.i03.04. 